\title{
Oxidation Performance and Interdiffusion Behavior of a Pt-Modified Aluminide Coating with Pre-deposition of $\mathrm{Ni}$
}

\author{
He Liu ${ }^{1,2}$. Shuai $\mathrm{Li}^{1,2} \cdot$ Cheng-Yang Jiang ${ }^{3}$. Chun-Tang $\mathrm{Yu}^{1,2} \cdot$ Ze-Bin Bao ${ }^{1} \cdot$ Sheng-Long Zhu ${ }^{1} \cdot$ Fu-Hui Wang ${ }^{3}$
}

Received: 7 March 2019 / Revised: 26 April 2019 / Published online: 27 May 2019

(c) The Chinese Society for Metals (CSM) and Springer-Verlag GmbH Germany, part of Springer Nature 2019

\begin{abstract}
To refrain the interdiffusion of elements while holding good oxidation resistance, a (Ni,Pt)Al/Ni composite coating was prepared by sequential treatments of electroplating $\mathrm{Ni}$ and $\mathrm{Pt}$ and successive gaseous aluminization. In comparison with normal $(\mathrm{Ni}, \mathrm{Pt}) \mathrm{Al}$ coating, high-temperature performance of the composite coating was evaluated in isothermal oxidation test at $1100^{\circ} \mathrm{C}$. Both the two coatings exhibited good resistance against high-temperature oxidation, but the interdiffusion of elements between composite coating and single-crystal (SC) superalloy substrate was greatly relieved, in which the thickness of secondary reaction zone (SRZ) and the amount of precipitated topologically close-packed phase in the SC alloy matrix were significantly decreased. Mechanisms responsible for delaying rate of coating degradation and SRZ growth/propagation are discussed.
\end{abstract}

Keywords Aluminide coating $\cdot$ Oxidation $\cdot$ Interdiffusion $\cdot$ Microstructure

\section{Introduction}

The second-generation Ni-based single-crystal (SC) superalloys, such as Rene N5 and CMSX-4, have been widely used as structural key components (e.g., turbine blades) in the hot section of aero engines due to its superior high-temperature mechanical properties [1]. Prior to application at high temperature, single-crystal superalloy components necessarily require sustainable protection against oxidation and hot corrosion, which could be achieved by utilizing protective metal coatings. To further improve the high-temperature performances, Pt-modified nickel aluminide coatings are extensively used in both land-based and aeronautical gas turbine engines $[2,3]$. Among the series of Pt-modified aluminide

Available online at http://link.springer.com/journal/40195

Ze-Bin Bao

zbbao@imr.ac.cn

1 Institute of Metal Research, Chinese Academy of Sciences, Shenyang 110016, China

2 School of Materials Science and Engineering, University of Science and Technology of China, Shenyang 110016, China

3 Shenyang National Laboratory for Materials Science, Northeastern University, Shenyang 110819, China coatings, single-phase $\beta$-(Ni,Pt)Al has been regarded promising for serving as the bond coat connecting top ceramic thermal barrier coating (TBC) by means of electron beam physical vapor deposition (EB-PVD) in industry $[4,5]$.

In the open literature, the studies of Pt-modified aluminide coating mostly focus on the beneficial effects of $\mathrm{Pt}$ in enhancing the oxidation performance, where some investigate the mechanisms causing the surface rumpling during cyclic oxidation tests [6-18]. Fountain et al. [7] reported that the $\mathrm{Pt}$ addition significantly improved oxidation resistance of the alloy containing aluminide coatings, while Meier et al. [9] reported that the enhanced cyclic oxidation behavior of platinum-modified coatings should be attributed to the platinum-enriched zone that promotes selective oxidation of aluminum and minimizes effect of other elements in the coating. The work done by Tawancy et al. [10] pointed out that platinum improves the protective nature of the coating by (1) increasing its diffusional stability, (2) eliminating chromium-rich precipitates from the outer coating layer and (3) preventing refractory transition elements such as Mo and W from diffusing into the outer coating layer. Besides positive effect of Pt incorporation, the platinum-modified aluminide coatings are reported to be susceptible to the development of surface rumpling under cyclic thermal exposure above $1100{ }^{\circ} \mathrm{C}$ [16], where the addition of reactive elements, such as $\mathrm{Hf}$, 
could substantially increase both the yield strength and creep resistance of the coating, thereby reducing the magnitude of rumpling [17].

In fact, beyond the surface undulation of growing oxide scale, the elemental interdiffusion between Pt-modified aluminide coating and SC substrate (inward diffusion of $\mathrm{Al}$ from coating to the substrate, and outward diffusion of Ni from substrate to coating) would undoubtedly decrease $\mathrm{Al}$ content in the coating and promote coating degradation from $\beta$-phase to $\gamma^{\prime}-\mathrm{Ni}_{3} \mathrm{Al}$. As $\gamma^{\prime}-\mathrm{Ni}_{3} \mathrm{Al}$ phase is Ni-rich and possesses inferior oxidation resistance, the elemental interdiffusions are detrimental to the overall oxidation performance of a coating prevailed by $\beta$ [19-23]. Additionally, the interdiffusion of $\mathrm{Al}$ and $\mathrm{Ni}$ between coating and substrate during extended thermal exposure destroys the coherent $\gamma / \gamma^{\prime}$ two-phase structure. Since solubility of refractory metals (for instance, $\mathrm{W}, \mathrm{Re}$, $\mathrm{Mo}$ and $\mathrm{Cr}$ ) in $\beta$ - and $\gamma^{\prime}$-phases is much lower than in $\gamma$, it is inevitable for precipitation of these elements as topologically close-packed (TCP) phases. The TCP precipitation is often associated with a discontinuous precipitation process whereby the migration of a high-angle grain boundary further results in the formation of a secondary reaction zone (SRZ). Commonly, the TCP precipitates with needle-like morphology are deemed harmful for hightemperature mechanical properties (e.g., creep rupture and fatigue lives) of SC superalloy because the strengthening elements in solid solution of the alloy are reduced and the precipitation of them causes intergranular embrittlement. Hence, the elemental interdiffusion between the Pt-modified aluminide coating and SC substrate plays a vital role in determining performance and life time of SC superalloy components. It is thus of great significance to inhibit or retard the elemental interdiffusion.

Many methods have been proposed to refrain the interdiffusion between protective metal coating and SC superalloy, including Re [24], Ir-Ta [25] or Ru [26, 27] modified aluminide coatings, and $\mathrm{AlN}$ [28], $\mathrm{Al}_{2} \mathrm{O}_{3}$ [29] and YSZ (yttria-stabilized zirconia) [30] serving as diffusion barrier. It is of high cost to use such precious metals, while those ceramic interlayers would increase the interface between coating and substrate. Besides, a concern is that the intrinsic brittleness and poor flexibility of direct ceramic diffusion barrier would give rise to high cracking tendency. To avoid such a drawback of embrittlement and reduce the cost, a $\beta-(\mathrm{Ni}, \mathrm{Pt}) \mathrm{Al} / \mathrm{Ni}$ composite coating was prepared on SC superalloy by simply adding a layer of $\mathrm{Ni}$ prior to depositing Pt plating, aiming to relieve the TCP precipitation in SC while holding good oxidation resistance. Oxidation behavior and microstructure evolution of the composite coating are investigated in comparison with normal $(\mathrm{Ni}, \mathrm{Pt}) \mathrm{Al}$, in which the beneficial effect of predeposited Ni plating is intensively discussed.

\section{Experimental}

Cylindrical specimens of $\Phi 15 \times 2.0 \mathrm{~mm}$ were machined from a second-generation single-crystal superalloy bar, in which the nominal composition is $\mathrm{Ni}-7.5 \mathrm{Co}, 7 \mathrm{Cr}, 6.5 \mathrm{Ta}$, 6.2Al, 5W, 3Re, $1.5 \mathrm{Mo}$ and $0.01 \mathrm{C}$ (wt.\%). The samples were ground consecutively using 240 and $400 \# \mathrm{SiC}$ papers and humidly blasted using 300-mesh alumina grit under $0.2 \mathrm{MPa}$, followed by ultrasonic cleaning in acetone and ethanol, respectively. After that, the SC samples with fresh surfaces were ready for electroplating with Ni layer.

The Ni layer with thickness of $25 \mu \mathrm{m}$ was deposited on the substrate alloy. Details of the bath composition and electroplating parameters for depositing $\mathrm{Ni}$ are summarized in Table 1. After that, the Ni-coated samples were electroplated with Pt layer of $5 \mu \mathrm{m}$ in thickness, followed by vacuum annealing treatment to reduce residual stress and dilute the Pt content on the surface. Then, a low activity vapor phase deposition (VPA) treatment was conducted in a vertical furnace filled with argon atmosphere. Annealing and aluminization details can be referred to our previous publication [30]. At last, a composite coating of $(\mathrm{Ni}, \mathrm{Pt}) \mathrm{Al}$ with $\mathrm{Ni}$ interlayer was acquired (namely, $(\mathrm{Ni}, \mathrm{Pt}) \mathrm{Al} / \mathrm{Ni}$ coating hereafter). For comparison, normal (Ni,Pt)Al coating specimens without Ni pre-deposition were prepared to evaluate their oxidation performance and interdiffusion behavior.

The oxidation performance of the two Pt-modified aluminide coatings was assessed isothermally at $1100^{\circ} \mathrm{C}$ using a muffle furnace in air. Coating specimens were placed in alumina crucibles which were all preheated at $1200{ }^{\circ} \mathrm{C}$ for enough time to ensure no further weight change in the following isothermal oxidation test. After a certain period, the samples were taken out from the muffle furnace and cooled down for $2 \mathrm{~h}$ in dry oven to room temperature. Then, an electronic balance with $10^{-5} \mathrm{~g}$ sensitivity was utilized to measure average mass change from three parallel samples at the oxidation intervals.

X-ray diffraction (XRD, X' Pert PRO, Cu $K_{\alpha}$ radiation at $40 \mathrm{kV}$, PANalytical, Almelo, Holland) was used to examine the phase constitution of the coatings before and after

Table 1 Parameters for Ni pre-deposition by electroplating technique

\begin{tabular}{ll}
\hline Parameter & Value \\
\hline $\mathrm{NiSO}_{4} \cdot 6 \mathrm{H}_{2} \mathrm{O}$ & $150-200 \mathrm{~g} \mathrm{~L}^{-1}$ \\
$\mathrm{NaCl}$ & $8-10 \mathrm{~g} \mathrm{~L}^{-1}$ \\
$\mathrm{H}_{2} \mathrm{BO}_{3}$ & $20-30 \mathrm{~g} \mathrm{~L}^{-1}$ \\
$\mathrm{Na}_{2} \mathrm{SO}_{4}$ & $50-80 \mathrm{~g} \mathrm{~L}^{-1}$ \\
$\mathrm{C}_{12} \mathrm{H}_{25} \mathrm{NaSO}_{4}$ & $0.1 \mathrm{~g} \mathrm{~L}^{-1}$ \\
$\mathrm{pH}_{\text {value }}$ & 5 \\
Temperature & $55{ }^{\circ} \mathrm{C}$ \\
Current density & $0.5-1 \mathrm{~A} \mathrm{dm}^{-2}$ \\
\hline
\end{tabular}


isothermal oxidation. Surface and cross-sectional morphologies and chemical composition of the samples were observed using a field emission scanning electron microscope (SEM, Inspect F50, FEI Co., Hillsboro, OR) equipped

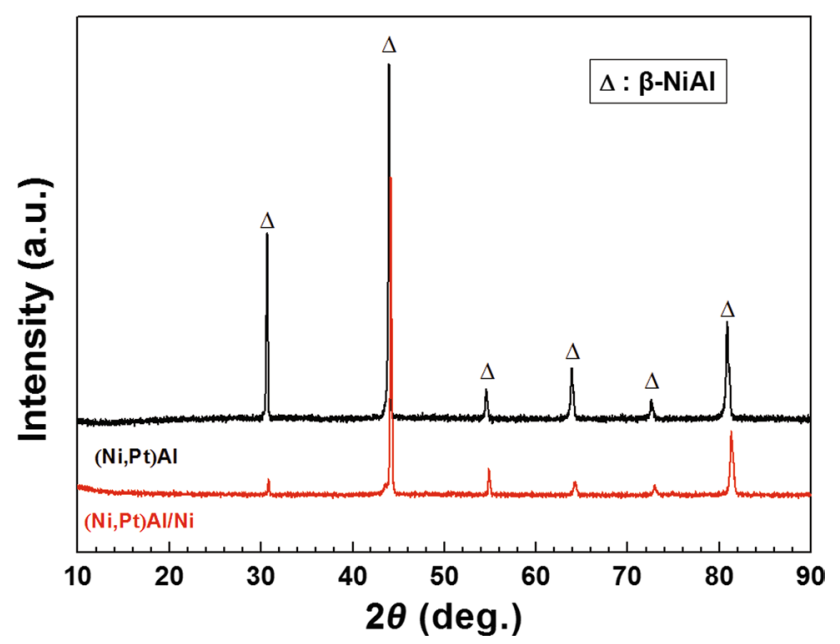

Fig. 1 XRD patterns of $\beta$-(Ni,Pt)Al coating specimens with and without Ni pre-deposition with energy-dispersive X-ray spectrometer (EDS, X-Max, Oxford Instruments Co., U.K.). The elemental distributions after oxidation were studied by electron probe microanalysis (EPMA-1610, Shimadzu, J. P.). For preserving the oxide scale from possible spallation, after oxidation the samples were deposited with a thin layer of electroless nickel and mounted in resin before cross-sectional observation.

\section{Results}

\subsection{Morphology and Phase Constitution of Coatings Before Oxidation}

Figure 1 shows the XRD patterns of the $\beta$-(Ni,Pt)Al coating specimens with and without $\mathrm{Ni}$ pre-deposition. It can be seen that the exclusive phase of both coatings is $\beta$-NiAl, which indicates Ni pre-deposition did not change the phase constitution of $(\mathrm{Ni}, \mathrm{Pt}) \mathrm{Al}$. Figure 2 shows the surface and cross-sectional morphologies of the as-received (Ni,Pt)Al and $(\mathrm{Ni}, \mathrm{Pt}) \mathrm{Al} / \mathrm{Ni}$ coatings. Figure $2 \mathrm{a}, \mathrm{b}$ shows that a similar surface morphology of visible grains is divided by grain boundary ridges on the two coatings. The average grain size
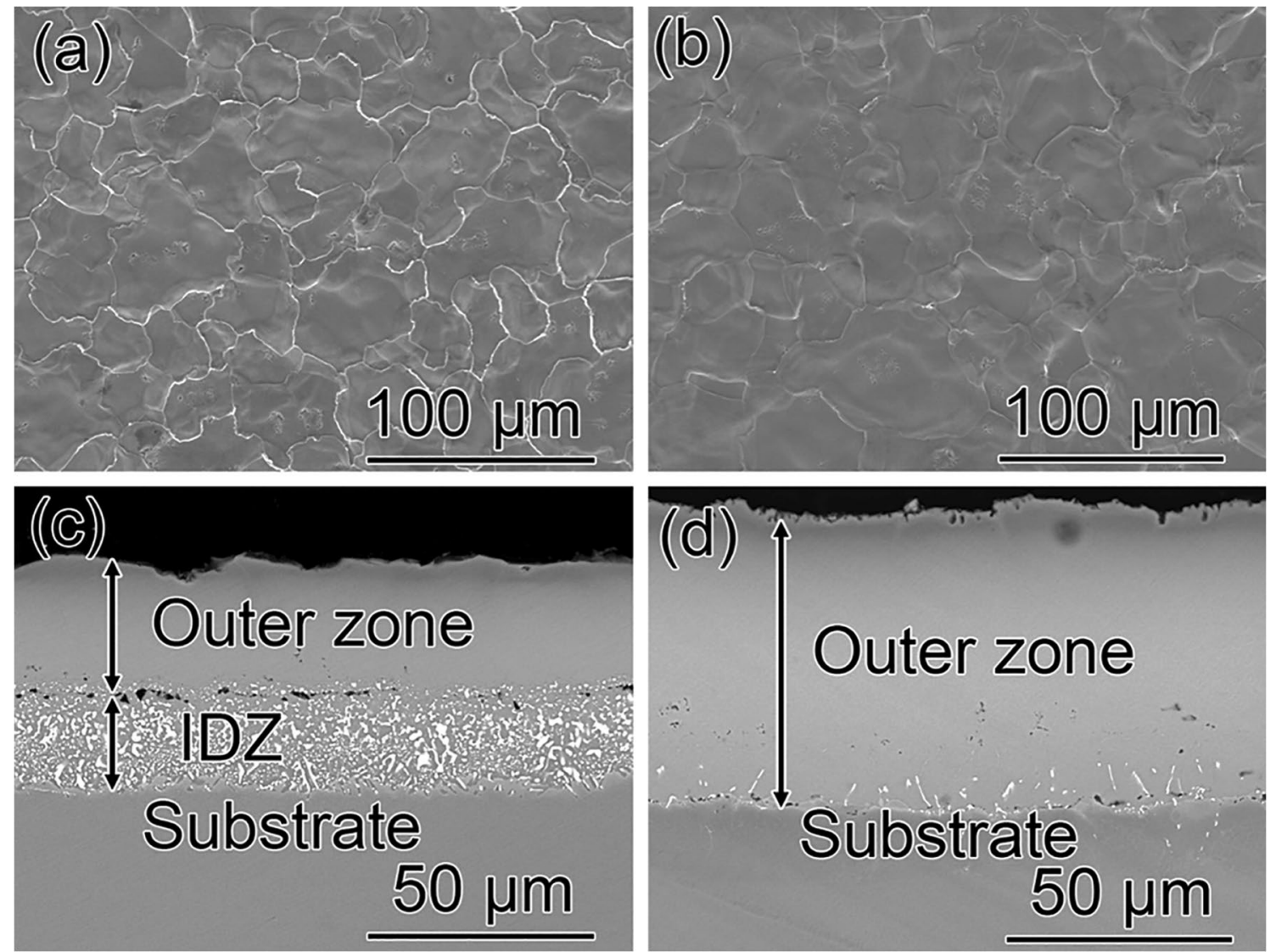

Fig. 2 Surface and cross-sectional morphologies of as-received (Ni,Pt)Al (a, c) and (Ni,Pt)Al/Ni coatings (b, d) 
of $(\mathrm{Ni}, \mathrm{Pt}) \mathrm{Al}$ coating is as same as that of $(\mathrm{Ni}, \mathrm{Pt}) \mathrm{Al}$ with $\mathrm{Ni}$ pre-deposition. However, there are some differences in the cross-sectional microstructure between the two coatings. As shown in Fig. 2c, a typical two-layer structure of normal $\beta$-(Ni,Pt)Al coating can be found: outer zone (OZ) with average thickness of $28 \mu \mathrm{m}$ and $17-\mu \mathrm{m}$ interdiffusion zone (IDZ). White TCP rods were precipitated in IDZ, above which the dark particles at OZ/IDZ interface were probably alumina grits due to surface blasting. In contrast, the $\beta-(\mathrm{Ni}, \mathrm{Pt}) \mathrm{Al} / \mathrm{Ni}$ coating consists of pure outer zone of about $60 \mu \mathrm{m}$ with no presence of IDZ. Below the top layer (OZ), some alumina grits were also observed at coating/substrate interface. The average compositions of $\mathrm{OZ}$, which were $5 \mu \mathrm{m}$ to surface, for both coatings are listed in Table 2. It can be seen that the average contents of $\mathrm{Al}$ and $\mathrm{Pt}$ in the two coatings are basically similar, and no element such as $\mathrm{Co}$ and $\mathrm{Cr}$ was identified in the outer zone of $(\mathrm{Ni}, \mathrm{Pt}) \mathrm{Al} / \mathrm{Ni}$ composite coating.

\subsection{Isothermal Oxidation Behavior}

Figure $3 \mathrm{a}$ shows the mass change curves of the two coatings at $1100^{\circ} \mathrm{C}$ for $1000 \mathrm{~h}$ in air. It can be seen that both of the coatings exhibited large mass gains after the first 20-h exposure, which was resulted from the fast formation of metastable oxide on the surface. After that, in stable oxidation stage the kinetic curves basically comply with parabolic law up to $1000 \mathrm{~h}$. The total mass gains

Table 2 Coating compositions measured at the region $5 \mu \mathrm{m}$ to the surface of the two coatings in as-received state (at.\%)

\begin{tabular}{llllll}
\hline & $\mathrm{Al}$ & $\mathrm{Ni}$ & $\mathrm{Pt}$ & $\mathrm{Cr}$ & $\mathrm{Co}$ \\
\hline (Ni,Pt)Al & 41.58 & 46.24 & 5.34 & 2.26 & 4.58 \\
$(\mathrm{Ni}, \mathrm{Pt}) \mathrm{Al} / \mathrm{Ni}$ & 42.91 & 51.56 & 5.52 & & \\
\hline
\end{tabular}

for the $(\mathrm{Ni}, \mathrm{Pt}) \mathrm{Al}$ and $(\mathrm{Ni}, \mathrm{Pt}) \mathrm{Al} / \mathrm{Ni}$ coatings after oxidation for $1000 \mathrm{~h}$ are 0.68 and $0.58 \mathrm{mg} \mathrm{cm}^{-2}$, respectively. Figure $3 \mathrm{~b}$ shows square of mass gains versus time calculated from the experiment data in Fig. 3a. To avoid influence of initial oxidation stage, data collected in the stable stage (from 40 to $1000 \mathrm{~h}$ ) were selected for linear fitting to get the oxidation rate constant $K_{\mathrm{p}}$. The $K_{\mathrm{p}}$ values for the $(\mathrm{Ni}, \mathrm{Pt}) \mathrm{Al}$ and $(\mathrm{Ni}, \mathrm{Pt}) \mathrm{Al} / \mathrm{Ni}$ coating were $4.02 \times 10^{-4}$ and $2.77 \times 10^{-4} \mathrm{mg}^{2} \mathrm{~cm}^{-4} \mathrm{~h}^{-1}$, respectively. Compared to the normal $\beta-(\mathrm{Ni}, \mathrm{Pt}) \mathrm{Al}$ coating, the mass gain of $\beta-(\mathrm{Ni}, \mathrm{Pt}) \mathrm{Al} /$ $\mathrm{Ni}$ coating showed a reduced oxidation rate with the exposure time. Figure 4 shows the XRD patterns of the two coating specimens after isothermal oxidation at $1100{ }^{\circ} \mathrm{C}$ for $1000 \mathrm{~h}$. Essentially, there is no difference for the diffraction peaks obtained on $\beta-(\mathrm{Ni}, \mathrm{Pt}) \mathrm{Al}$ and $\beta-(\mathrm{Ni}, \mathrm{Pt}) \mathrm{Al} /$ $\mathrm{Ni}$ coating specimens. The oxide scales both belonged

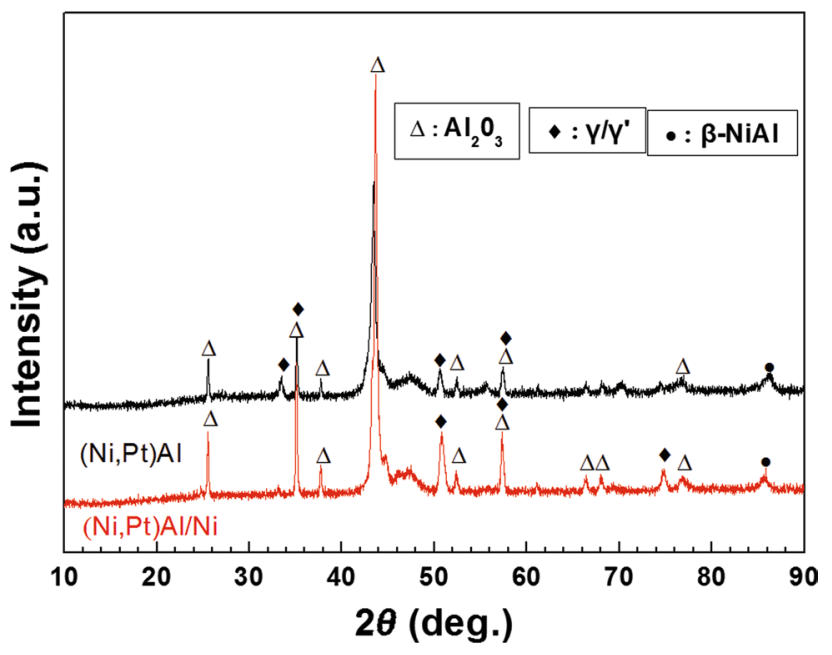

Fig. 4 XRD patterns for $(\mathrm{Ni}, \mathrm{Pt}) \mathrm{Al}$ and $(\mathrm{Ni}, \mathrm{Pt}) \mathrm{Al} / \mathrm{Ni}$ coatings after isothermal oxidation test at $1100^{\circ} \mathrm{C}$ for $1000 \mathrm{~h}$
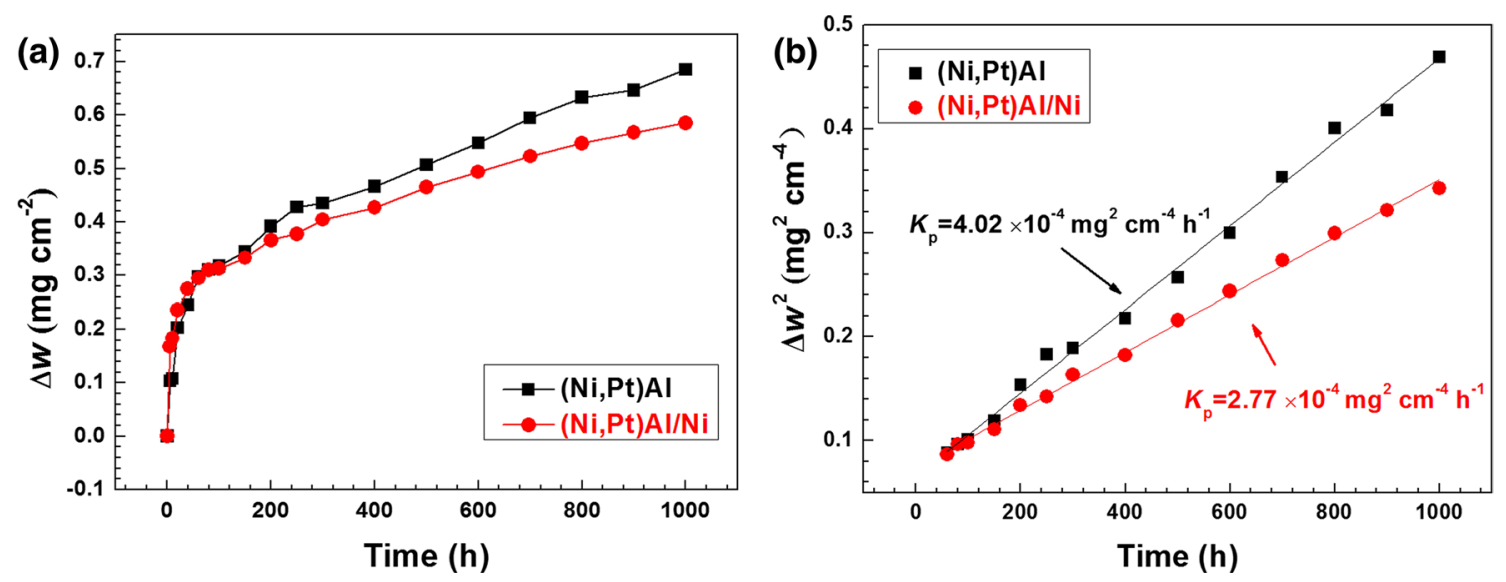

Fig. 3 Mass gain $(\Delta w)(\mathbf{a})$ and square of mass gain $(\mathbf{b})$ of $(\mathrm{Ni}, \mathrm{Pt}) \mathrm{Al}$ and $(\mathrm{Ni}, \mathrm{Pt}) \mathrm{Al} / \mathrm{Ni}$ coating specimens during isothermal oxidation test at $1100{ }^{\circ} \mathrm{C}$ 
to exclusive $\alpha-\mathrm{Al}_{2} \mathrm{O}_{3}$, and the coating phases comprised dominant $\gamma / \gamma^{\prime}$ and slightly remained $\beta$-NiAl.

Cross-sectional morphologies of the both coatings after oxidation at $1100{ }^{\circ} \mathrm{C}$ for $1000 \mathrm{~h}$ are shown in Fig. 5 . As shown in Fig. 5a, the oxide scale formed on normal $(\mathrm{Ni}, \mathrm{Pt}) \mathrm{Al}$ coating specimen was generally continuous, but some cracks inside or beneath the alumina scale can be observed. After oxidation for $1000 \mathrm{~h}$, the thickness of outer zone was about $35 \mu \mathrm{m}$, above which the IDZ thickness was about $20 \mu \mathrm{m}$. Beneath the IDZ, a secondary reaction zone consisting of high-quantity needle-like TCP precipitates was formed in the SC substrate, whose thickness is approximately $96 \mu \mathrm{m}$.

In contrast, the oxide scale formed on surface of $(\mathrm{Ni}, \mathrm{Pt})$ $\mathrm{Al} / \mathrm{Ni}$ composite coating was adhesively continuous without any crack as shown in Fig. 5b. The average thickness of oxide scale formed on $(\mathrm{Ni}, \mathrm{Pt}) \mathrm{Al} / \mathrm{Ni}$ composite coating was about $3.1 \mu \mathrm{m}$, which is much thinner than that of normal $(\mathrm{Ni}, \mathrm{Pt}) \mathrm{Al}(5.5 \mu \mathrm{m})$. The thickness of outer layer for $(\mathrm{Ni}, \mathrm{Pt}) \mathrm{Al} / \mathrm{Ni}$ composite coating was $55 \mu \mathrm{m}$, while the thickness of IDZ was about $20 \mu \mathrm{m}$ (same to normal (Ni,Pt) $\mathrm{Al})$. Satisfyingly, the SZR thickness beneath $(\mathrm{Ni}, \mathrm{Pt}) \mathrm{Al} /$ $\mathrm{Ni}$ composite coating after $1000 \mathrm{~h}$ oxidation was $55 \mu \mathrm{m}$, which indicates a $43 \%$ reduction to the normal $(\mathrm{Ni}, \mathrm{Pt}) \mathrm{Al}$.

After oxidation at $1100{ }^{\circ} \mathrm{C}$ for $1000 \mathrm{~h}$, the average compositions (at the region $5 \mu \mathrm{m}$ to surface) of each coating are listed in Table 3. It can be seen that the residual Al content of the (Ni,Pt)Al/Ni composite coating was much higher than that of normal $(\mathrm{Ni}, \mathrm{Pt}) \mathrm{Al}$ coating. Higher amount of $\mathrm{Al}$ content in the coating is commonly deemed to be potential in acquiring longer service life. According to the experimental results after oxidation for $1000 \mathrm{~h}$, better performance in the long-time oxidation test could be observed on the $(\mathrm{Ni}, \mathrm{Pt}) \mathrm{Al}$ coating with $\mathrm{Ni}$ pre-deposition.
Table 3 Coating compositions measured at the region $5 \mu \mathrm{m}$ to the surface of the two coatings after isothermal oxidation at $1100{ }^{\circ} \mathrm{C}$ for $1000 \mathrm{~h}($ at. \%)

\begin{tabular}{llllll}
\hline & $\mathrm{Al}$ & $\mathrm{Ni}$ & $\mathrm{Pt}$ & $\mathrm{Cr}$ & $\mathrm{Co}$ \\
\hline$(\mathrm{Ni}, \mathrm{Pt}) \mathrm{Al}$ & 26.61 & 60.45 & 4.99 & 3.36 & 4.6 \\
$(\mathrm{Ni}, \mathrm{Pt}) \mathrm{Al} / \mathrm{Ni}$ & 33.6 & 54.59 & 5.41 & 3.08 & 3.33 \\
\hline
\end{tabular}

\subsection{Characteristic of Interdiffusion Zone Evolution During Isothermal Oxidation}

In order to specifically identify interdiffusion behavior between coating and SC substrate, cross-sectional morphologies of the two coatings after oxidation at $1100{ }^{\circ} \mathrm{C}$ for $0 \mathrm{~h}, 20 \mathrm{~h}$ and $500 \mathrm{~h}$ are shown in Figs. 6 and 7. As shown in Fig. 6a, the interdiffusion zone (IDZ) is about $20 \mu \mathrm{m}$, which consists of $\beta$-matrix and blocky TCP precipitates. As the oxidation time extended to $20 \mathrm{~h}$, the TCP precipitates became coarser and the thickness of IDZ grew up to $25 \mu \mathrm{m}$. Beneath the IDZ, a 4- $\mu$ m-thick SRZ with a large number of needle-like precipitates can be observed in the substrate shown in Fig. 6b. After 500 h, the thickness of IDZ did not increase any more, and instead, the SRZ expanded greatly. The average length of the needle-like TCP precipitates was about $7 \mu \mathrm{m}$, and the thickness of SRZ in the SC alloy increased from $4 \mu \mathrm{m}$ after $20 \mathrm{~h}$ to approximately $57 \mu \mathrm{m}$ after $500 \mathrm{~h}$ (shown in Fig. 6c), which accompanied with densification of needle-like TCP precipitates.

Figure 7 shows cross-sectional morphologies of the $\beta$-(Ni,Pt)Al/Ni coating after oxidation at $1100{ }^{\circ} \mathrm{C}$ for $0 \mathrm{~h}$, $20 \mathrm{~h}$ and $500 \mathrm{~h}$. As shown in Fig. 7a, there is fundamentally no emergence of IDZ below the coating. After oxidation for $20 \mathrm{~h}$, IDZ emerged out with thickness of about $25 \mu \mathrm{m}$ (shown in Fig. 7b). When the oxidation time extended to
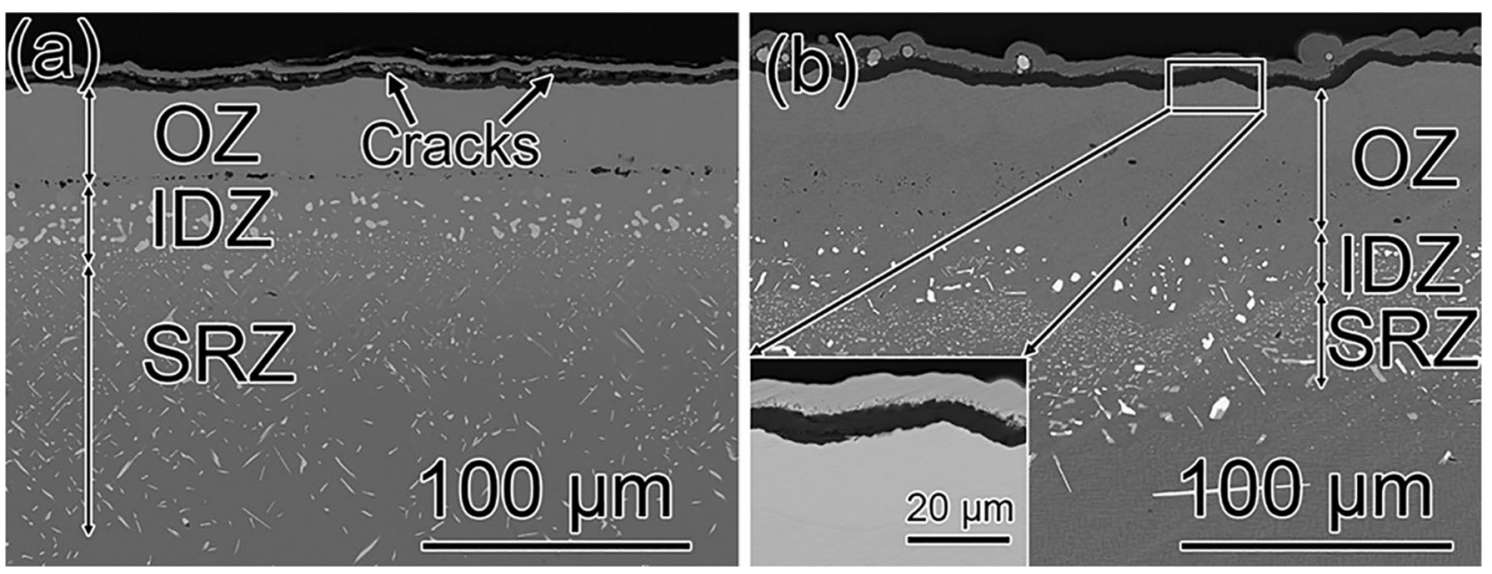

Fig. 5 Cross-sectional morphologies of $(\mathrm{Ni}, \mathrm{Pt}) \mathrm{Al}(\mathbf{a})$ and $(\mathrm{Ni}, \mathrm{Pt}) \mathrm{Al} / \mathrm{Ni}(\mathbf{b})$ coating specimens after isothermal oxidation test at $1100{ }^{\circ} \mathrm{C}$ for $1000 \mathrm{~h}$ 

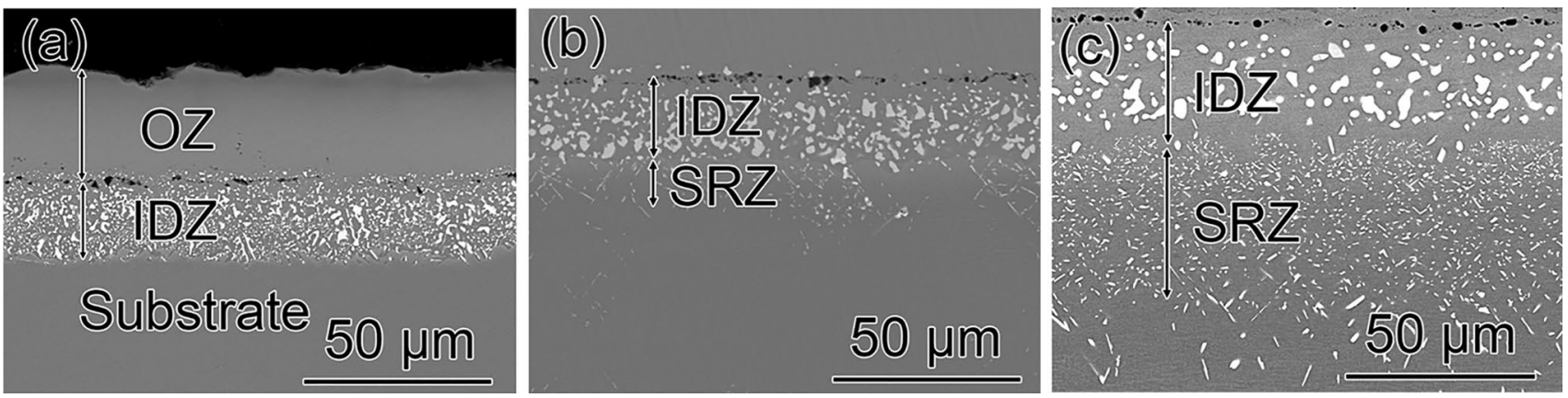

Fig. 6 Interdiffusion zone evolution of normal $\beta$-(Ni,Pt)Al coating specimen during isothermal oxidation test at $1100{ }^{\circ} \mathrm{C}$ for a $0 \mathrm{~h}, \mathbf{b} 20 \mathrm{~h}, \mathbf{c}$ $500 \mathrm{~h}$
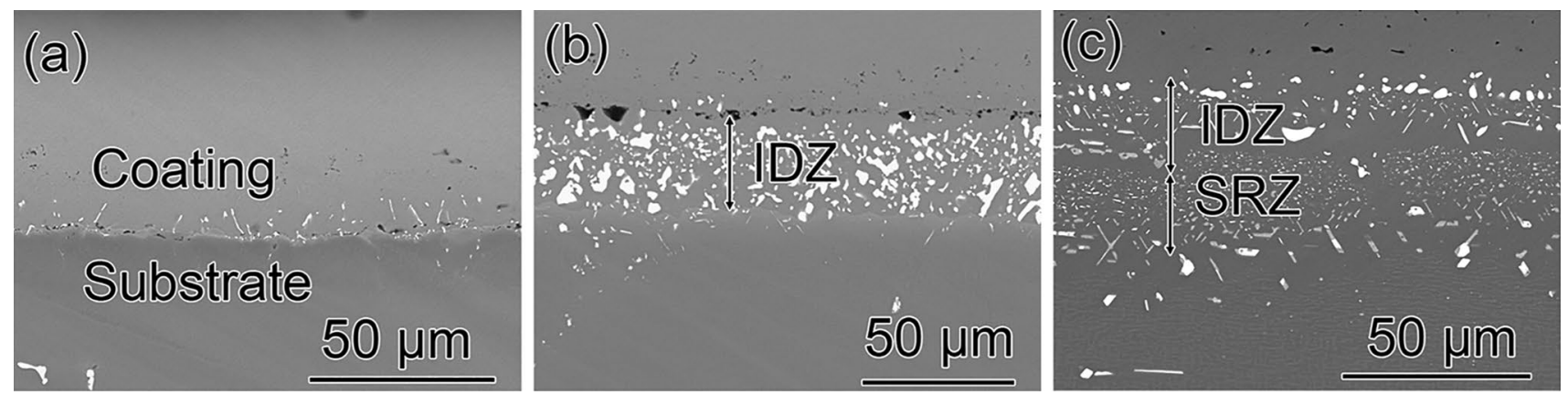

Fig. 7 Interdiffusion zone evolution of (Ni,Pt)Al/Ni composite coating during isothermal oxidation test at $1100{ }^{\circ} \mathrm{C}$ for $\mathbf{a} 0 \mathrm{~h}, \mathbf{b} 20 \mathrm{~h}, \mathbf{c} 500 \mathrm{~h}$

$500 \mathrm{~h}$, the thickness of IDZ did not change, while the thickness of SRZ in the alloy increased to about $31 \mu \mathrm{m}$ (shown in Fig. 7c). The average length of the TCP precipitates in the alloy was about $2 \mu \mathrm{m}$, which is much smaller than the counterparts formed in case of normal $(\mathrm{Ni}, \mathrm{Pt}) \mathrm{Al}$ coating shown in Fig. 6c.

\subsection{Mapping of Elements After Oxidation for $500 \mathrm{~h}$}

As shown in Figs. 8 and 9, the distributions of main elements after the isothermal oxidation test for $500 \mathrm{~h}$ were obtained using electron probe microanalysis. Figure 8 shows that a continuous alumina scale formed on the surface of $\beta$-(Ni,Pt) $\mathrm{Al}$ coating. Considering the XRD results together, after oxidation the coating consisted of two phases: One had higher $\mathrm{Al}$ content which belonged to $\beta$-NiAl and another with lower $\mathrm{Al}$ content belonged to $\gamma^{\prime}-\mathrm{Ni}_{3} \mathrm{Al}$ phase. Differed by that, the relative volume fractions of $\beta-\mathrm{NiAl}$ and $\gamma^{\prime}-\mathrm{Ni}_{3} \mathrm{Al}$ in normal (Ni,Pt)Al were individually $70 \%$ and $30 \%$. Beneath the alumina scale, no appearance of degraded $\gamma^{\prime}-\mathrm{Ni}_{3} \mathrm{Al}$ phase could be observed, which implies good oxidation resistance of $(\mathrm{Ni}, \mathrm{Pt}) \mathrm{Al}$ coating in high-temperature oxidation. $\mathrm{Co}$ successfully diffused from the SC substrate to entirely the whole coating. The presence of $\mathrm{Pt}$ was mainly enriched in the $\beta$-zone of the outer coating. Other elements like $\mathrm{Cr}, \mathrm{W}$ and Re were mainly segregated in IDZ and SRZ, and only a few amounts of $\mathrm{Cr}$ and $\mathrm{W}$ could be detected in the coating.

In case of $\beta-(\mathrm{Ni}, \mathrm{Pt}) \mathrm{Al} / \mathrm{Ni}$ coating after oxidation for $500 \mathrm{~h}$, it can be observed that the phase transformation from $\beta$ - to $\gamma^{\prime}$-phase still occurred in the outer zone, but the volume fractions of $\beta-\mathrm{NiAl}$ and $\gamma^{\prime}-\mathrm{Ni}_{3} \mathrm{Al}$ were $90 \%$ and $10 \%$, respectively. This implies the degradation rate from $\beta$ to $\gamma^{\prime}$ became slower. Compared to normal (Ni,Pt)Al, the enriching degrees of $\mathrm{Co}, \mathrm{Cr}, \mathrm{W}$ and $\mathrm{Re}$ were smaller in the outer $(\mathrm{Ni}, \mathrm{Pt}) \mathrm{Al} / \mathrm{Ni}$ coating after identical time of oxidation test.

\section{Discussion}

The interdiffusion between the coating and superalloy usually leads to two detrimental effects: Firstly, it deteriorates the oxidation resistance of the coating due to the meaningless inward diffusion of $\mathrm{Al}$ and the harmful outward diffusion of refractory elements, such as $\mathrm{W}$ and Mo; secondly, it deteriorates mechanical properties of the $\mathrm{SC}$ substrate due to the formation of needle-like TCP precipitates in SRZ. Just as expectation, the specifically designed $\beta$-(Ni,Pt)Al/Ni coating showed superior isothermal oxidation performance including high integrity and adhesion of alumina scale, and lesser precipitation of needle-like TCP precipitates in thinner SRZ. 


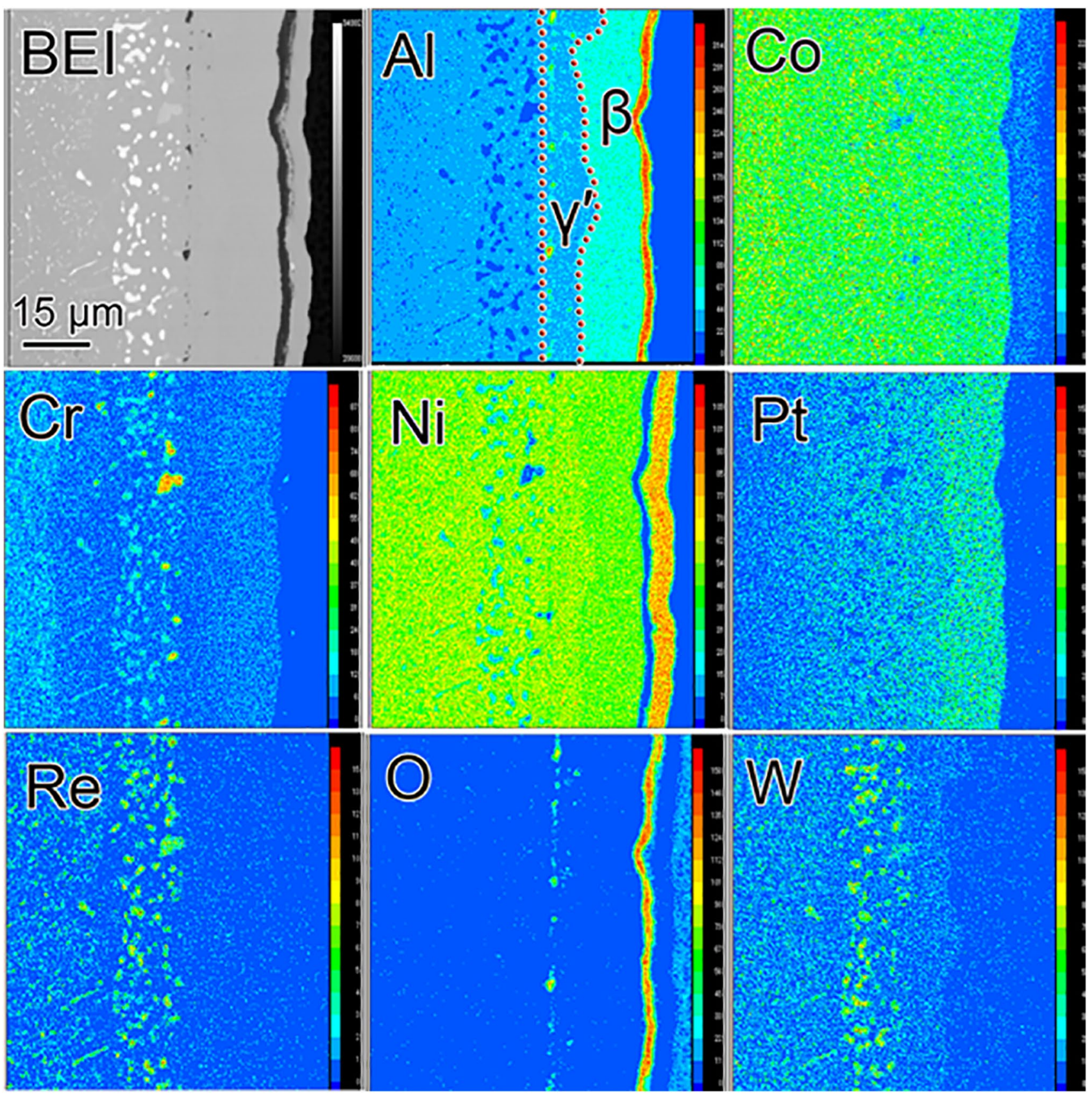

Fig. 8 Elemental mappings of $(\mathrm{Ni}, \mathrm{Pt}) \mathrm{Al}$ coating specimen after isothermal oxidation at $1100^{\circ} \mathrm{C}$ for $500 \mathrm{~h}$

The elemental interdiffusion between the (Ni,Pt)Al/Ni coating and SC substrate has been greatly relieved. The mechanisms for delaying coating degradation rate and SRZ growth/ propagation rate will be discussed in the following.

\subsection{Influence of Ni Pre-deposition on Oxidation Behavior}

Compared with normal $\beta$-(Ni,Pt)Al coating, the mass gain curve for $\beta-(\mathrm{Ni}, \mathrm{Pt}) \mathrm{Al} / \mathrm{Ni}$ coating showed a reduced oxidation rate with the exposure time (shown in Fig. 3). The thickness of the oxide scale of $(\mathrm{Ni}, \mathrm{Pt}) \mathrm{Al}$ coating with $\mathrm{Ni}$ predeposition was much thinner than that of normal (Ni,Pt)Al. There is almost no crack in the alumina scale developed on the surface of (Ni,Pt)Al/Ni coating (Fig. 5), and the reason should be distributed to the refrained outward diffusions of refractory elements such as W. As most of refractory metal oxides are volatile, outward diffusion of them to the surface frontier would destroy integrity of alumina scale and is regarded to be very harmful to the adhesion of protective 


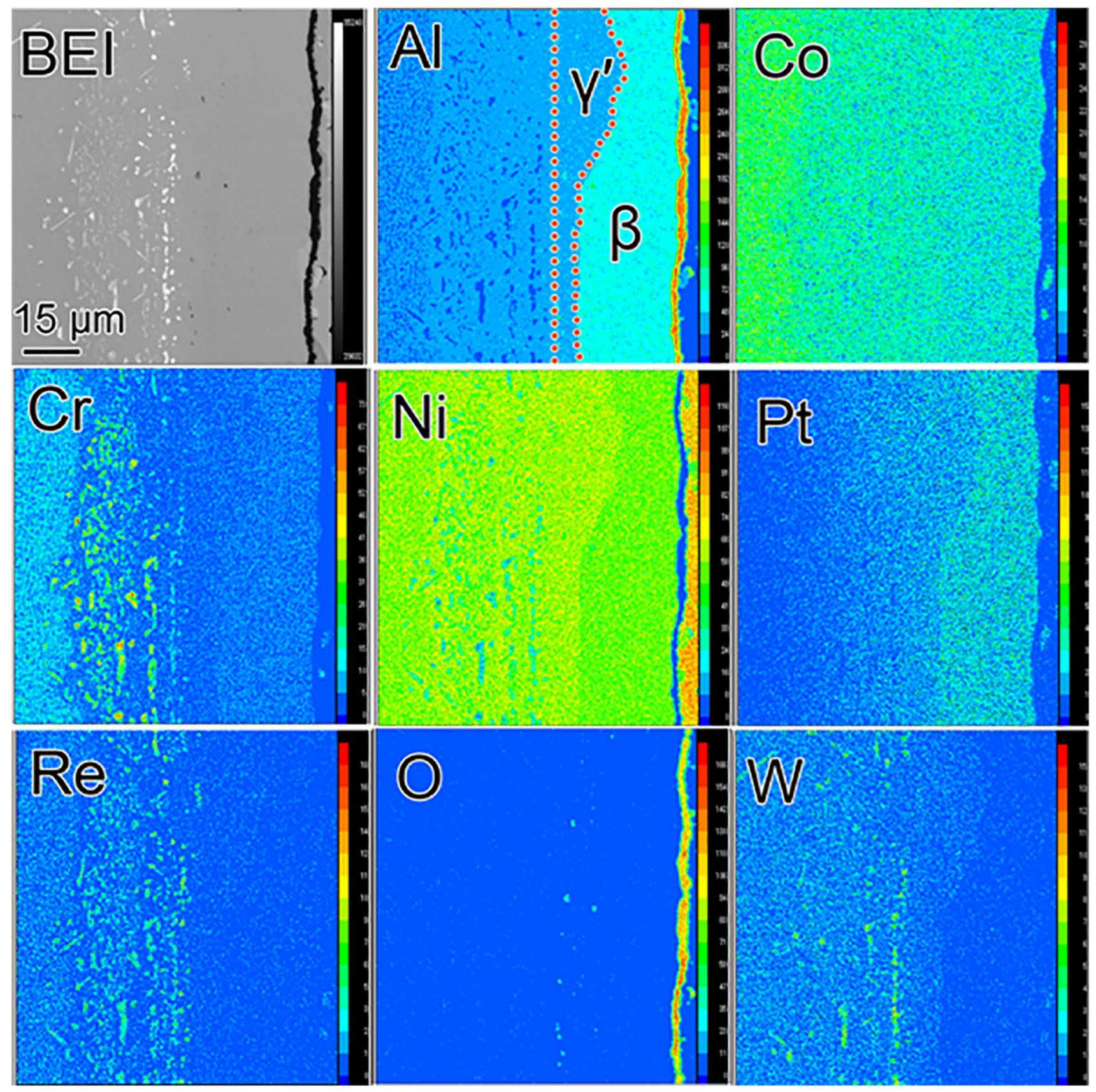

Fig. 9 Elemental mappings of (Ni,Pt)Al/Ni coating specimen after isothermal oxidation test at $1100^{\circ} \mathrm{C}$ for $500 \mathrm{~h}$

$\alpha-\mathrm{Al}_{2} \mathrm{O}_{3}$ scale. In SC superalloys, refractory elements prefer to stay in $\gamma$-matrix, and the Ni pre-deposition could maximally stabilize these elements in IDZ. Therefore, during the oxidation test for $1000 \mathrm{~h}$ the $(\mathrm{Ni}, \mathrm{Pt}) \mathrm{Al} / \mathrm{Ni}$ composite coating showed better scale spallation resistance due to clean constitution of elements in outer zone of coating.

During isothermal oxidation, the phase transformation from $\beta$ to $\gamma^{\prime}$ occurs in the outer zone of coating. The EDS results listed in Table 3 show that the content of $\mathrm{Al}$ in the $\beta-(\mathrm{Ni}, \mathrm{Pt}) \mathrm{Al} / \mathrm{Ni}$ coatings was higher than that in the normal
$\beta$-(Ni,Pt)Al coating. This can be explained by lesser consumption of $\mathrm{Al}$ at surface since the alumina scale grown on $(\mathrm{Ni}, \mathrm{Pt}) \mathrm{Al} / \mathrm{Ni}$ coating was more integrate and adherent. As $\alpha-\mathrm{Al}_{2} \mathrm{O}_{3}$ grows at an extremely slow rate, it demands limited amount of $\mathrm{Al}$ to participate in thickening of TGO (thermally grown oxide). However, once defects like cracking occur in alumina scale, it would consume higher amount of $\mathrm{Al}$ to repair the broken alumina scale. Besides, the EPMA results shown in Figs. 8 and 9 confirm 30\% and 10\% of degraded $\gamma^{\prime}$-phase for normal (Ni,Pt)Al coating and $(\mathrm{Ni}, \mathrm{Pt}) \mathrm{Al} / \mathrm{Ni}$ after 
isothermal oxidation at $1100{ }^{\circ} \mathrm{C}$ for $500 \mathrm{~h}$, which evidently verifies a positive effect of delaying coating degradation for $\beta$-(Ni,Pt)Al by Ni pre-deposition.

\subsection{Influence of Ni Pre-deposition on SRZ Formation}

Figure 10 shows the SRZ thicknesses of the two coatings after oxidation at $1100^{\circ} \mathrm{C}$ for $20 \mathrm{~h}, 300 \mathrm{~h}, 500 \mathrm{~h}$ and $1000 \mathrm{~h}$. A general trend is that the SRZ thickness of $\beta-(\mathrm{Ni}, \mathrm{Pt}) \mathrm{Al} /$ $\mathrm{Ni}$ coating was smaller than that of normal $\beta$-(Ni,Pt)Al. For normal $(\mathrm{Ni}, \mathrm{Pt}) \mathrm{Al}$ coating, the formation of SRZ could be observed after oxidation for $20 \mathrm{~h}$, followed by dramatic thickening of SRZ up to $1000 \mathrm{~h}$. On the contrary, there was no formation of SRZ after $20 \mathrm{~h}$, and the increment of SRZ thickness was relatively lower with proceeding the oxidation test from 100 to $1000 \mathrm{~h}$. This undoubtedly confirms the beneficial effect in delaying SRZ formation of (Ni,Pt)Al-coated SC superalloy by Ni pre-deposition.

Since the growth of SRZ is a diffusion-controlled process, during $1000 \mathrm{~h}$ oxidation the thickness of SRZ conforms to one-dimensional diffusion equation [22]:

$d_{\mathrm{SRZ}}^{2}+d_{\mathrm{SRZ} 0}^{2}=k \times t$

where $d_{\mathrm{SRZ}}$ represents the SRZ thickness, $d_{\mathrm{SRZ} 0}$ represents the initial SRZ thickness, $k$ is the diffusivity and $t$ is the time. The equation can be used to determine an approximate value for the diffusivity $[32,33]$. As for normal $\beta-(\mathrm{Ni}, \mathrm{Pt}) \mathrm{Al}$ coating, the calculated parabolic coefficient $k$ of SRZ propagation is equal to $1.29 \times 10^{-11} \mathrm{~m}^{2} \mathrm{~s}^{-1}$, which is much higher than that of the $\beta$-(Ni,Pt)Al/Ni coating $\left(4.15 \times 10^{-12} \mathrm{~m}^{2} \mathrm{~s}^{-1}\right)$.

As the interdiffusion of elements between $(\mathrm{Ni}, \mathrm{Pt}) \mathrm{Al} / \mathrm{Ni}$ coating and SC substrate had been greatly relieved, the total thickness of SRZ after long-time thermal exposure could be

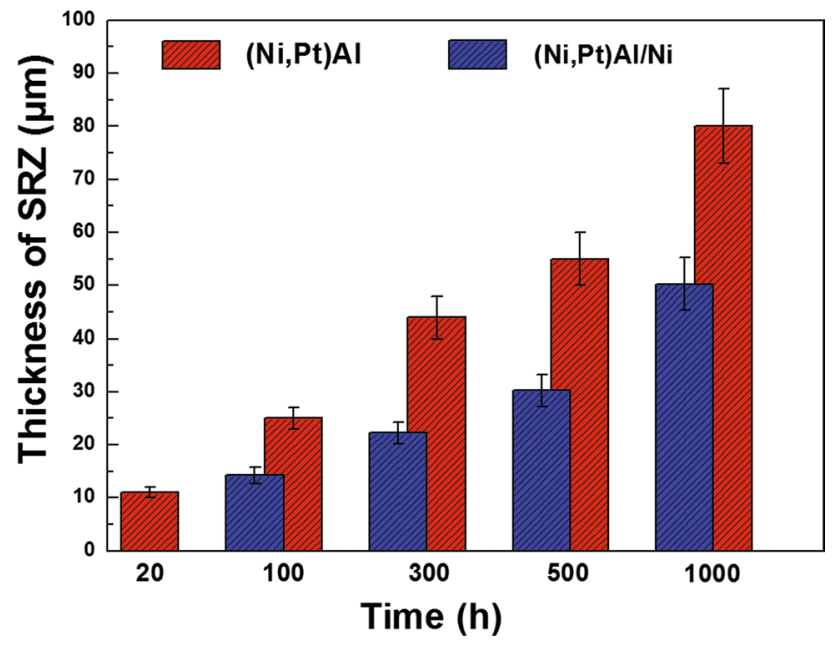

Fig. 10 Evolution of SRZ thickness for (Ni,Pt)Al/Ni and (Ni,Pt)Al coating specimens during isothermal oxidation test significantly decreased as well. Two reasons are responsible for the mitigated interdiffusion rate between $(\mathrm{Ni}, \mathrm{Pt}) \mathrm{Al} /$ $\mathrm{Ni}$ and SC substrate. Firstly, there was no IDZ formation beneath the $\beta-(\mathrm{Ni}, \mathrm{Pt}) \mathrm{Al} / \mathrm{Ni}$ coating during the aluminization process due to Ni pre-deposition, as shown in Fig. 2d. The formation of SRZ under $\beta$-(Ni,Pt)Al/Ni coating has been postponed to after oxidation for $100 \mathrm{~h}$ (shown in Fig. 10). Secondly, as shown in Table 1 , for $\beta$-(Ni,Pt)Al/Ni coating, there was no element such as $\mathrm{Co}$ and $\mathrm{Cr}$ found in the outer layer after vapor phase aluminization, which indicates outward diffusion of Co was mitigated by $\mathrm{Ni}$ pre-deposition. It has been reported that increasing Co content in Ni-based superalloy would restrict the precipitation of TCP phases during high-temperature exposure [34]. Combined with reported beneficial effect of Co in refraining TCP precipitation, the lower degree of SRZ formation in the alloy was partly due to the stabilized Co-presence in the SC alloy.

\subsection{Various Mechanisms and Propagations of SRZ}

Figures 11 and 12 show the schematic illustrations of SRZ growth for the two coatings in the current study. As shown in Fig. 11, in aluminization process an outer $\beta$-(Ni,Pt) Al layer forms on SC superalloy by the reaction of outwardly diffused $\mathrm{Ni}$ with externally supplied $\mathrm{Al}[35,36]$. The original $\gamma / \gamma^{\prime}$-microstructures in SC substrate are destroyed due to absorption of $\mathrm{Al}$ and loss of $\mathrm{Ni}$, where a series of phase transformations occur, forming TCP rods and $\beta$-matrix in the IDZ [37]. It is well known that $\beta$-phase possesses much lower solubility for refractory elements, such as $\mathrm{Cr}, \mathrm{W}$, Mo and Re, than $\gamma$-phase [38-40]. When $\gamma / \gamma^{\prime}$ transforms to $\beta$-phase, the refractory elements will precipitate out and segregate as particles or rods. Accordingly, Mo, W and Re will be precipitated as TCP particles in IDZ [41, 42] (shown in Fig. 11a). In early-stage oxidation, the interdiffusion continues to occur between the coating and the SC substrate, in which the $\mathrm{Al}$ atoms diffuse from the outer zone to the substrate and the $\mathrm{Ni}$ atoms diffuse conversely. Apparently, the SRZ formed beneath the IDZ is still driven by the elemental interdiffusion, in which a cellular transformation would happen by the inward diffusion of $\mathrm{Al}$ from the coating [33]. In this case, the phase transformation from $\gamma / \gamma^{\prime}$ to $\beta$ is replaced by transformation from $\gamma / \gamma^{\prime}$ to $\gamma^{\prime}$ since the interdiffusion fluxes become too low to support $\gamma / \gamma^{\prime}$ - to $\beta$-phase (shown in Fig. 11b). When the interdiffusion fluxes become too low to sustain the IDZ growth, the SRZ will appear beneath the IDZ, as illustrated in Fig. 11b. Figure 11c shows the secondary reaction zone consisted of high-quantity needle-like TCP precipitates grows thicker during the stable stage of oxidation, and $\beta$-phase of outer zone partly degrades to $\gamma^{\prime}$-phase by alumina formation and interdiffusion (shown in Fig. 8).

A different manner of SRZ formation for $(\mathrm{Ni}, \mathrm{Pt}) \mathrm{Al} / \mathrm{Ni}$ coating is shown in Fig. 12. The Ni pre-deposition layer acts 


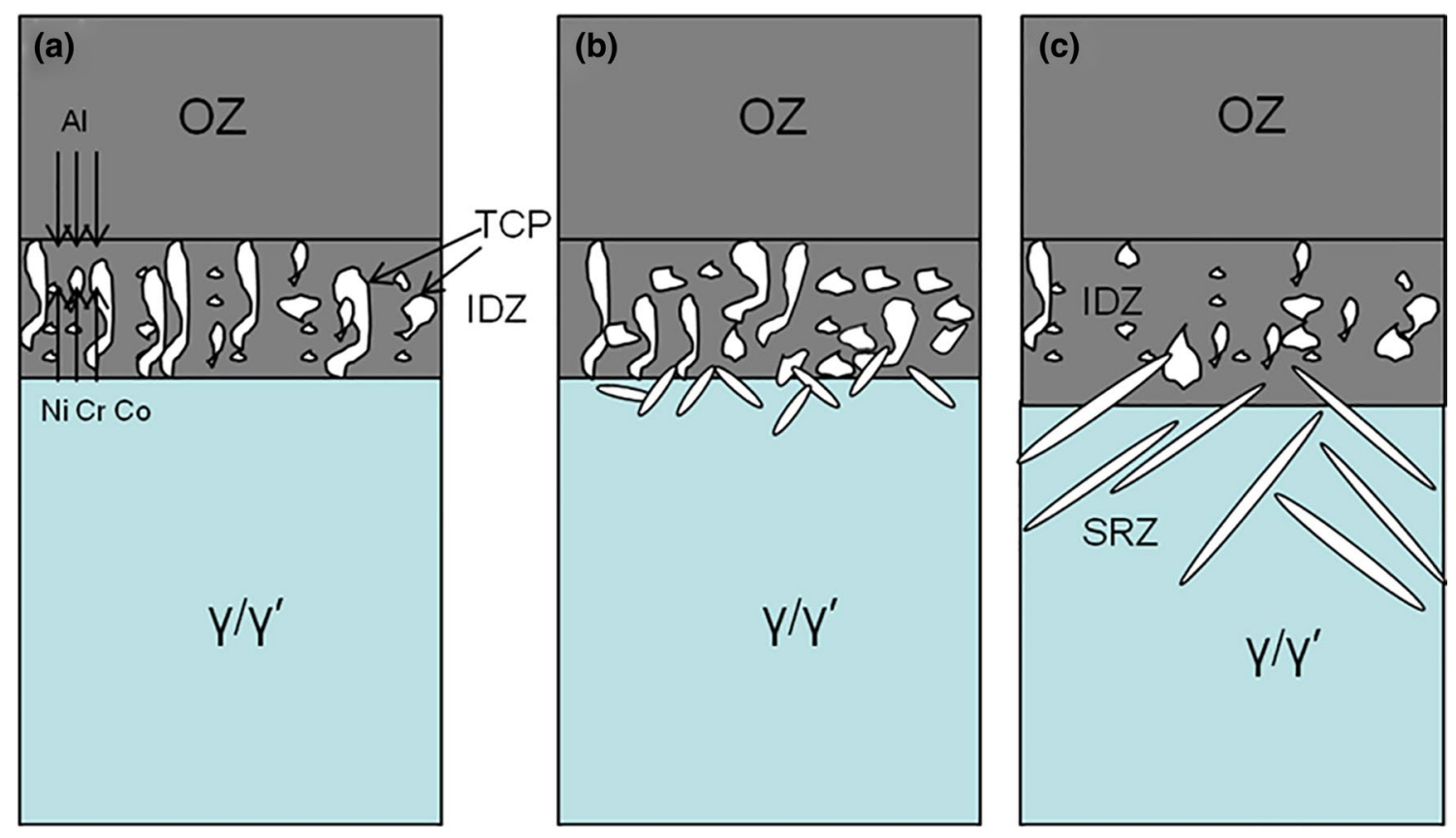

Fig. 11 Schematic illustration showing evolution of SRZ developed below normal (Ni,Pt)Al coating
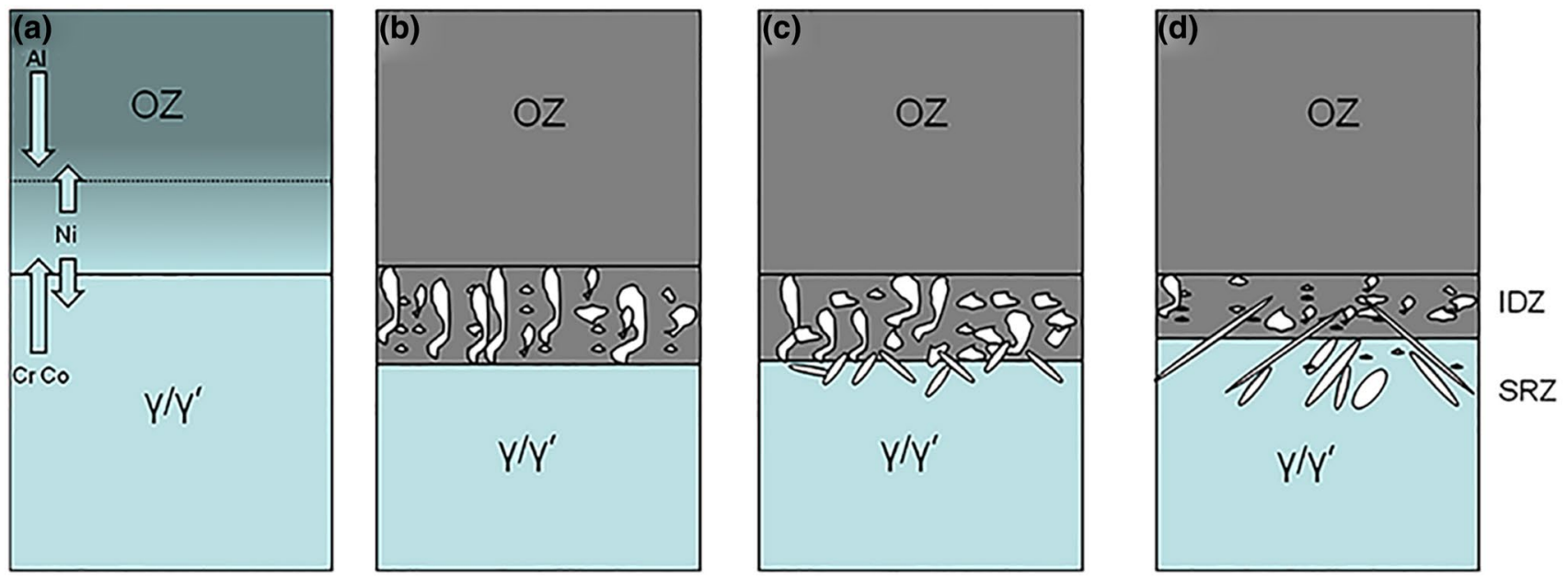

Fig. 12 Schematic illustration showing evolution of SRZ developed below (Ni,Pt)Al/Ni coating

as the buffering source to replace Ni outward diffusion from the SC substrate during aluminization, i.e., the diffusions of $\mathrm{Ni}, \mathrm{Co}$ and $\mathrm{Cr}$ from the substrate to coating are somehow refrained. The formation of $(\mathrm{Ni}, \mathrm{Pt}) \mathrm{Al}$ out layer is mainly supported by the pre-deposited Ni plating. As minimal Ni atoms participated in outward diffusion, the $\gamma / \gamma^{\prime}$-coherent structure in the SC substrate is thus stable, resulting in the absence of IDZ (shown in Fig. 12a). Figure 2d shows the $\beta$-(Ni,Pt)Al/Ni coating consists of pure outer zone of about $60 \mu \mathrm{m}$ with no presence of IDZ. In early stage of oxidation, because of the fast diffusion fluxes of $\mathrm{Al}$ from the coating to the substrate and the $\mathrm{Ni}$ in opposite direction, in substrate the $\gamma / \gamma^{\prime}$-structure transforms into $\beta$-phase. Then, the refractory metals have to precipitate out as TCP particles in IDZ (shown in Fig. 12b). In stable oxidation stage, SRZ will form in the form of needle-like TCP phases by the slower diffusion fluxes (Fig. 12c) followed by the thickening and growth of SRZ (Fig. 12d). The intrinsic advantage, which is interesting in the present study, is that the amount and average size of the TCP precipitates in both IDZ and SRZ were smaller in the coating with Ni pre-deposition (Fig. 4). The reason is that the fraction of $\gamma$-phase in the SC substrate of the $\beta-(\mathrm{Ni}, \mathrm{Pt}) \mathrm{Al} / \mathrm{Ni}$ coating was much greater than that in the $\beta$-(Ni,Pt)Al coating due to the extra supplement of $\mathrm{Ni}$. As 
the solid solubility of refractory metals in $\gamma$-phase is much higher than those in $\beta$ - and $\gamma^{\prime}$-phase, higher fraction of $\gamma$ could preserve more $\mathrm{Re}$ or $\mathrm{Cr}$ in the form of solid solution, avoiding the growth of lengthy TCP precipitates. Therefore, the amount and size of TCP phase are smaller below the $(\mathrm{Ni}, \mathrm{Pt}) \mathrm{Al} / \mathrm{Ni}$ composite coating.

\section{Conclusions}

1. A single-phase $\beta$ - $(\mathrm{Ni}, \mathrm{Pt}) \mathrm{Al} / \mathrm{Ni}$ composite coating was prepared via sequential treatments of electroplating $\mathrm{Ni}$ and $\mathrm{Pt}$ and successive vapor phase aluminization. In comparison with normal (Ni,Pt)Al coating, isothermal oxidation behavior and microstructure evolution of the composite coating were evaluated at $1100{ }^{\circ} \mathrm{C}$ for $1000 \mathrm{~h}$. Better oxidation performance was observed on the $(\mathrm{Ni}, \mathrm{Pt}) \mathrm{Al} / \mathrm{Ni}$ composite coating, which showed lower rates of oxidation and degradation with continuously adherent $\alpha-\mathrm{Al}_{2} \mathrm{O}_{3}$ on surface.

2. The interdiffusion of the elements between $(\mathrm{Ni}, \mathrm{Pt}) \mathrm{Al} / \mathrm{Ni}$ coating and SC substrate was greatly relieved, in which the thickness of SRZ and the amount of precipitated TCP phase in the alloy matrix were decreased significantly.

3. In single-crystal superalloy, the formation of IDZ was driven by high-rate elemental interdiffusion and slower interdiffusion led to emergence of SRZ, which accompanied with phase transformations from $\gamma / \gamma^{\prime}$ to $\beta$ and from $\gamma / \gamma^{\prime}$ to $\gamma^{\prime}$, respectively.

Acknowledgements This work was financially supported by the National Natural Science Foundation of China (Nos. 51671202 and 51301184) and the "Liaoning BaiQianWan Talents" Program.

\section{References}

[1] M.J. Pomeroy, Mater. Des. 26, 223 (2005)

[2] J.H. Sun, H.C. Jang, E. Chang, Surf. Coat. Technol. 64, 195 (1994)

[3] R.G. Wing, I.R. Mcgill, Plat. Eng. 53, 15 (1981)

[4] S. Darzens, D.R. Mumm, D.R. Clarke, A.G. Evans, Metall. Mater. Trans. A 34, 511 (2003)

[5] S.K. Gong, L. Deng, F.S. Liu, H.B. Xu, Acta Metall. Sin. (Engl. Lett.) 9, 519 (1996)

[6] E.J. Felten, F.S. Pettit, Oxid. Met. 10, 189 (1976)

[7] J.G. Fountain, F.A. Golightly, F.H. Stott, G.C. Wood, Oxid. Met. 10, 341 (1976)

[8] D.K. Das, V. Singh, S.V. Joshi, Oxid. Met. 57, 245 (2001)

[9] G.H. Meier, F.S. Pettit, Surf. Coat. Technol. 39, 1 (1989)

[10] H.M. Tawancy, N.M. Abbas, T.N. Rhys-Jones, Surf. Coat. Technol. 49, 1 (1991)
[11] H.M. Tawancy, N. Sridhar, B.S. Tawabini, N.M. Abbas, T.N. Rhys-Jones, J. Mater. Sci. 27, 6463 (1992)

[12] H.M. Tawancy, N. Sridhar, N.M. Abbas, D. Rickerby, Scr. Metall. Mater. 33, 1431 (1995)

[13] J.A. Haynes, B.A. Pint, Y. Zhang, I.G. Wright, Oxid. Met. 58, 513 (2002)

[14] Y. Zhang, W.Y. Lee, J.A. Haynes, I.G. Wright, B.A. Pint, K.M. Cooley, P.K. Liaw, Metall. Mater. Trans. A 30, 2679 (1999)

[15] C. Leyens, B.A. Pint, I.G. Wright, Surf. Coat. Technol. 133, 15 (2000)

[16] V.K. Tolpygo, D.R. Clarke, Scr. Mater. 57, 563 (2007)

[17] V.K. Tolpygo, K.S. Murphy, D.R. Clarke, Acta Mater. 56, 489 (2008)

[18] M.W. Chen, M.L. Glynn, R.T. Ott, T.C. Hufnagel, K.J. Hemker, Acta Mater. 51, 4279 (2003)

[19] J. Angenete, K. Stiller, E. Bakchinova, Surf. Coat. Technol. 176, $272(2004)$

[20] D. Wang, H. Peng, S.K. Gong, H.B. Guo, Corros. Sci. 78, 304 (2014)

[21] B. Bai, H.B. Guo, H. Peng, L.Q. Peng, S.K. Gong, Corros. Sci. 53, 2721 (2011)

[22] D.K. Das, K.S. Murphy, S.W. Ma, T. Pollock, Metall. Mater. Trans. A 39, 1647 (2008)

[23] Y. Matsuoka, K. Chikugo, T. Suzuki, Y. Matsunaga, S. Taniguchi, Mater. Sci. Forum 512, 111 (2006)

[24] F. Lang, T. Narita, Intermetallics 15, 599 (2007)

[25] F. Wu, H. Murakami, A. Suzuki, Surf. Coat. Technol. 168, 62 (2003)

[26] Y. Wang, H.B. Guo, H. Peng, L.Q. Peng, S.K. Gong, Intermetallics 19, 191 (2011)

[27] Z.M. Bai, D.Q. Li, H. Peng, J. Wang, H.B. Guo, S.K. Gong, Prog. Nat. Sci. Mater. Int. 146, 37 (2012)

[28] L.J. Zhu, S.L. Zhu, F.H. Wang, Corros. Sci. 60, 265 (2012)

[29] J. Müller, M. Schierling, E. Zimmermann, D. Neuschütz, Surf. Coat. Technol. 120, 16 (1999)

[30] T.Q. Liang, H.B. Guo, H. Peng, S.K. Gong, J. Alloys Compd. 509, $8542(2011)$

[31] Y.F. Yang, C.Y. Jiang, Z.B. Bao, S.L. Zhu, F.H. Wang, Corros. Sci. 106, 43 (2016)

[32] Y. Matsuoka, Y. Aoki, K. Matsumoto, A. Satou, T. Suzuki, K. Chikugo, K. Murakami, Superalloys 12(637), 637-642 (2004)

[33] J.D. Nystrom, T.M. Pollock, W.H. Murphy, A. Garg, Metall. Mater. Trans. A 28, 2443 (1997)

[34] Q.Y. Shi, X.F. Ding, M.L. Wang, Y.R. Zheng, J.P. He, S. Tin, Q. Feng, Metall. Mater. Trans. A 45, 1833 (2013)

[35] V.A. Esin, V. Maurel, P. Breton, A. Köster, S. Selezneff, Acta Mater. 105, 505 (2016)

[36] F. Pedraza, A.D. Kennedy, J. Kopecek, P. Moretto, Surf. Coat. Technol. 200, 4032 (2006)

[37] T.Q. Liang, H.B. Guo, H. Peng, S.K. Gong, Surf. Coat. Technol. 205, 4374 (2011)

[38] W. Huang, Y.A. Chang, Mater. Sci. Eng. A 259, 110 (1999)

[39] M. Reid, M.J. Pomeroy, J.S. Robinson, J. Mater. Process. Technol. 153, $660(2004)$

[40] D.B. Zhang, S.K. Gong, H.B. Xu, Y.F. Han, Acta Metall. Sin. (Engl. Lett.) 15, 45 (2002)

[41] C.M.F. Rae, R.C. Reed, Acta Mater. 49, 4113 (2001)

[42] J.X. Yang, Q. Zheng, X.F. Sun, H.R. Guan, Z.Q. Hu, Mater. Sci. Eng. A 465, 100 (2007) 